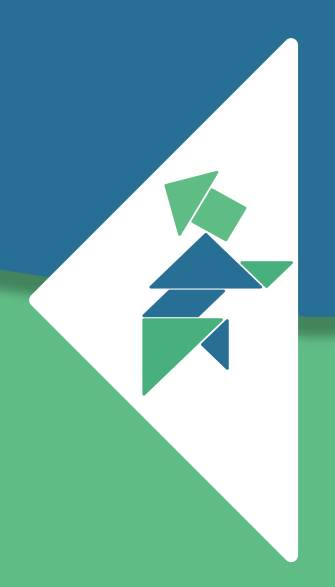

\title{
Fisioterapia respiratória em lactente hospitalizado com Síndrome de Stickler: um estudo de caso
}

Chestphysiotherapy in hospitalized infant with Stickler's Syndrome: Case report
FisiSenectus. Unochapecó Ano 1 - Edição especial - 2013 p. $104-108$

\section{Janaína Dalla Costa Zaions}

Fisioterapeuta, Universidade Regional Integrada do Alto Uruguai e das Missões, Erechim, janazaions@gmail.com.

\section{Helena Bianchi}

Acadêmica do curso de Fisioterapia, Universidade Regional Integrada do Alto Uruguai e das Missões, Erechim, helena01bianchi@hotmail.com.

\section{Gisele Maiara Zuravski}

Acadêmica do curso de Fisioterapia, Universidade Regional Integrada do Alto Uruguai e das Missões, Erechim, giselezuravski@hotmail.com.

\section{Fernanda Dal'Maso Camera}

Mestre em Ciências, Universidade Regional Integrada do Alto Uruguai e das Missões, Erechim,ferdalmaso@hotmail.com.

\section{Ana Lucia Bernardo de Carvalho Morsch}

Mestre em Ciências, Universidade Regional Integrada do Alto Uruguai e das Missões, Erechim, analuepm@yahoo.com.br.

\section{Ana Laura Nicoletti Carvalho Petry}

Doutora em Ciências, Universidade Regional Integrada do Alto Uruguai e das Missões,

Erechim, analauranc@yahoo.com.br.

\section{Resumo}

Introdução: A Síndrome de Stickler é uma desordem do tecido conjuntivo de herança autossômica dominante, com expressão variável, que acomete ambos os sexos e crianças com antecedentes familiares da doença possuem $50 \%$ de chance de desenvolvê-la, sendo sua prevalência variável. Caracteriza-se por face plana, fissura palatina, miopia intensa com descolamento de retina e catarata, perda auditiva, artropatia com displasia espôndiloepifisária, maxilar curto, olhos proeminentes, pregas epicantais, depressão do dorso nasal e micrognatia. A pneumonia é uma das complicações que podem ocorrer nesses pacientes. É a principal causa de mortes em crianças, sendo uma doença frequente em todo o mundo, afetando principalmente, e com maior gravidade, a população pediátrica de países em desenvolvimento. Objetivos: Devido a literatura escassa sobre a atuação fisioterapêutica nessa síndrome, realizou-se um estudo de caso com o objetivo de relatar a eficácia e segurança de técnicas de fisioterapia respiratória em paciente traqueostomizado hospitalizado, portador da Síndrome de Stickler, com diagnóstico médico de pneumonia. Materiais e métodos: Foram analisados os sinais vitais 
pré e pós-técnicas de fisioterapia. 0 tratamento fisioterapêutico foi composto por 11 atendimentos diários, com duração de aproximadamente 45 minutos, no qual foram utilizadas as seguintes técnicas: tapotagem bilateral e vibrocompressão torácica manual bilateral, aceleração do fluxo expiratório seguida de aspiração da traqueostomia associada a hiperinsuflação manual. Resultados: Como resultado se obteve redução da frequência cardíaca e respiratória, aumento da saturação periférica de oxigênio, além da melhora da ausculta pulmonar. Conclusão: Com isso, ressalta-se a importância da Fisioterapia Respiratória no tratamento da pneumonia em lactentes hospitalizados em relação à melhora de trocas gasosas e redução do desconforto respiratório.

\title{
Palavras-chave
}

Pierre Robin. Pneumonia. Hereditária.

\begin{abstract}
Introduction: The Stickler syndrome is a connective tissue disorder with autossomal dominant inheritance with variable expression, affecting both sexes and children with a family history of disease have a 50\% chance of developing it, and it has a variable prevalence. It is characterized by flat face, cleft palate, severe myopia with retinal detachment and cataracts, hearing loss, arthropathy espondiloepifisária dysplasia, short jaw, prominent eyes, epicantais folds, depressed nasal dorsum, and micrognathia. Pneumonia is one of the complications that can occur in these patients. It is the leading cause of death in children, and a common disease in the world, affecting mainly, and more severe, the pediatric population in developing countries. Due to the scarce literature on both chest physiotherapy in this syndrome., It has analysed theefficacy and safety ofchest physiotherapy inhospitalized patients with tracheostomy, Stickler's syndrome, with a diagnosis of pneumonia.Tothis end, weanalyzed vital signs before and after chest physiotherapy. Objective: The physical therapy consisted of eleven daily sessions, during approximately forty-five minutes where were used the following techniques: tapping and manual bilateral thoracic vibration, followed by aspiration of tracheos tomy associated with manual hyperinflation and expiratory flow acceleration. Results: As a result, we observed decreased valuesin heart rate and breathing rate, increased values of oxygen saturation, as well as improved pulmonary auscultation. Conclusion: Thus, it emphasizes the importance of a respiratory therapy program in the treatment of pneumonia in hospitalized infants when it comes to improvement of gas exchange and reduce respiratory distress.
\end{abstract}

\section{Keywords}

Pierre Robin. Pneumonia. Hereditary.

\section{Introdução}

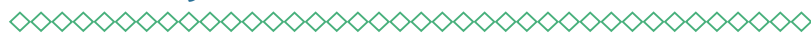

A Síndrome de Stickler trata-se de uma desordem do tecido conjuntivo de herança autossômica dominante, com expressão variável. Inicialmente foi descrita por Gunner Stickler em 1965. Esta síndrome acomete ambos os sexos e crianças com antecedentes familiares da doença possuem 50\% de chance de desenvolvê-la. Sua prevalência é variável, já que há autores que indicam ocorrência de $1: 10.000$ e outros $2: 10.000^{1-3}$.

É caracterizada por face plana, fissura palatina, miopia intensa com descolamento de retina e catarata, perda auditiva e artropatia com displasia espondiloepifisária. Miopia de moderada a severa é encontrada em $75 \%$ a $80 \%$ dos pacientes, descolamento total da retina está presente em mais da metade dos pacientes, podendo ocorres de forma espontânea ou durante ato operatório, para correção de catarata. Ainda são encontrados astigmatismo (60\%), catarata (45\%), estrabismo $(30 \%)$ e glaucoma $(10 \%)^{1,3}$. O Complexo de Pierre Robin se expressa por obstrução das vias aéreas e dificuldades alimentares, podendo a criança apresentar desde leve dificuldade respiratória e alimentar até graves crises de asfixia. Para tratamento dessas alterações várias modalidades são descritas na literatura como tratamento postural (posição prona), 
intubação nasofaríngea, glossopexia, traqueostomia e, mais recentemente, distração mandibular ${ }^{4}$.

A pneumonia (PN) é uma das complicações que pode ocorrer nesses pacientes. Essa complicação é a principal causa de mortes em crianças, sendo uma doença frequente em todo o mundo, afetando principalmente, e com maior gravidade, a população pediátrica de países em desenvolvimento ${ }^{5-8}$.

A fisioterapia respiratória em pediatria começou a ser desenvolvida na década de 1950, e a partir de 1970 criou-se técnicas específicas para pacientes pediátricos, principalmente para auxiliar a desobstrução brônquica em pacientes com fibrose cística ${ }^{9}$. É uma modalidade terapêutica relativamente recente dentro das enfermarias pediátricas, estando em fase de expansão em razão dos seus benefícios. Sua atuação tem papel fundamental na prevenção e intervenção das complicações que ocorrem em pacientes com sinais clínicos de pneumonia, além de ser uma solução simples, acessível, de baixo custo e que não exige tecnologia nem recursos terapêuticos sofisticados para sua execução ${ }^{7}$. A fisioterapia tem como principal objetivo auxiliar na remoção das secreções da árvore brônquica, diminuir a resistência das vias aéreas, melhorar as trocas gasosas e, consequentemente, reduzir o trabalho respiratório9 ${ }^{9}$.

O objetivo deste estudo foi relatar a eficácia e segurança de técnicas de fisioterapia respiratória em paciente traqueostomizado hospitalizado, portador da Síndrome de Stickler, com diagnóstico médico de pneumonia. Para tal foram analisadas os sinais vitais pré e pós-técnicas de fisioterapia.

\section{Apresentação do caso}

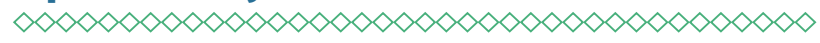

0 presente artigo caracteriza-se como estudo de caso e foi realizado nas dependências de um hospital do município de Erechim (RS), durante o estágio curricular do curso de Fisioterapia, no mês de agosto, totalizando 11 sessões de fisioterapia realizadas diariamente no período da manhã, com duração de aproximadamente 45 minutos cada sob a supervisão de professoras fisioterapeutas docentes do curso.

Paciente com diagnóstico clínico de pneumonia, oito meses de idade, sexo masculino, portador da Síndrome de Stickler e procedente de Barão de Cotegipe (RS). Deu entrada hospitalar no dia 6 de agosto de 2011 por hipertermia. Segundo informações colhidas com a mãe do paciente, a gestação foi planejada e desejada, o parto foi normal e a criança nasceu a termo. Segundo o prontuário médico, ao nascer o paciente apresentou índice de Apgar 8 e 9. Logo após o nascimento, permaneceu internado evoluindo com disfunção respiratória, sendo necessária intubação orotraqueal. 0 paciente foi encaminhado ao Hospital das Clínicas em Porto Alegre (RS), permanecendo internado por dois meses, onde realizou correção cirúrgica da mandíbula, colocação de traqueostomia e distratores mandibulares para correção de micrognatia. Além disso, o paciente apresenta fenda palatina, fístula traqueobrônquica e glossoptose, caracterizando, então, a Síndrome de Stickler.

No dia 8 de agosto de 2011, encontrou-se o paciente no colo da mãe, traqueostomizado com cânula Portex ${ }^{\circledR} \mathrm{n}^{\circ} 4$, ventilando em ar ambiente, corado, prostrado e choroso. Ao exame físico observou-se padrão respiratório misto, abdômen globoso, expansibilidade torácica simétrica, com leve batimento de asa de nariz. Sinais vitais: frequência cardíaca $(F C)$ : 95 batimentos por minuto (bpm), frequência respiratória (FR): 45 incursões respiratórias por minuto (irpm), saturação periférica de oxigênio $\left(\mathrm{SpO}_{2}\right)$ : $92 \%$ e ausculta pulmonar com murmúrio vesicular presente bilateralmente com roncos difusos. De acordo com a mãe, a criança apresentava tosse eficaz produtiva.

Exames complementares do dia 6 de agosto de 2011: raio-X de tórax: infiltrado peri e infra-hilar bilateral; hemograma apresentando eritropenia e leucograma normal.

0 protocolo de atendimento seguiu-se em uma sequência que foi mantida durante todos os atendimentos. Inicialmente, a ficha do paciente foi analisada, com visualização de exames laboratoriais e raio- $X$ de tórax quando presentes, e em seguida verificação dos sinais vitais do paciente, ausculta pulmonar e tratamento fisioterapêutico com técnicas de fisioterapia respiratória.

A partir dos dados da avaliação foi estabelecida uma estratégia de intervenção, com os seguintes objetivos: higiene brônquica, melhora das trocas gasosas, prevenção de complicações respi- 
ratórias. As manobras fisioterapêuticas realizadas foram: tapotagem bilateral e vibrocompressão torácica manual bilateral, ambas 5 minutos bilateralmente seguida de aspiração da traqueostomia associada à hiperinsuflação manual e aceleração do fluxo expiratório (AFE), com cinco séries de oito repetições.

Foram registrados $\mathrm{FC}$ e $\mathrm{SpO}_{2}$ por meio de um oxímetro. FR pela observação da expansibilidade torácica durante um minuto. Essas variáveis foram mensuradas em dois momentos: antes e após cada intervenção fisioterapêutica.

\section{Resultados}

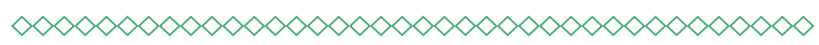

A Tabela 1 demonstra os valores da FC, FR e $\mathrm{SpO}_{2}$, antes e após as técnicas fisioterapêuticas em cada sessão. É possível observar uma redução na FC (- $4 \%)$ e FR $(-5,59 \%)$ antes e após a realização das técnicas de fisioterapia respiratória, bem como aumento nos valores de $\mathrm{SpO}_{2}(+5,34 \%)$. Em relação a ausculta pulmonar, verificou-se que no dia da avaliação fisioterapêutica a criança apresentava-se com murmúrio vesicular presente com roncos difusos e após os 11 dias de tratamento apresentou-se com murmúrio vesicular presente sem ruídos adventícios.

Durante o procedimento de aspiração da traqueostomia, a secreção aspirada era de aspecto mucopurulento, espessa e em grande quantidade, já nos dois últimos atendimentos observou-se secreção mucoide, fluída e em pequena quantidade.

\section{Discussão}

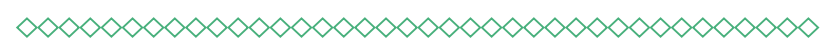

A fisioterapia respiratória em pediatria vem sendo estudada desde a década de 1970, e o paciente em questão apresentou melhora do seu quadro clínico no decorrer de cada atendimento. Como pode ser visto na Tabela 1, a FC e FR diminuíram após as técnicas de fisioterapia e a $\mathrm{SpO}_{2}$ apresentou aumento. Em relação à ausculta pulmonar ao final de cada atendimento havia diminuição dos roncos e no último atendimento ausência de ruídos adventícios.
As manobras de higiene brônquica são utilizadas para mobilizar e remover as secreções nas vias aéreas, no sentido de melhorar a função pulmonar. Brunetto ${ }^{7}$ afirma que o tratamento da pneumonia consiste em: fluidificação e mobilização das secreções através de exercícios respiratórios, mudança de decúbito, tapotagem de forma cuidadosa e aspiração endotraqueal ou por meio da cânula de traqueostomia, caso necessário.

Em um ensaio clínico randomizado de Gomes e Costa $(2010)^{10}$, com 30 lactentes internados com diagnóstico de bronquiolite viral aguda, avaliados pelo escore de Wang (CS) de 0 (normal) até 12 (grave), no pré e pós-atendimento fisioterapêutico imediato. Os lactentes foram divididos em três grupos com $n=10$, a saber: técnicas convencionais (G1 com drenagem postural modificada, compressão expiratória, vibração e percussão), técnicas atuais (G2 com expiração lenta e prolongada e desobstrução rinofaríngea retrógrada) e somente aspiração de vias aéreas (G3). Foram encontradas diferenças estatisticamente significantes entre o pré e pós-intervenção imediata do $\mathrm{G} 1(7,5 / 5,5)$ $(p=0,002)$ e do $G 2(7,0 / 4,0)(p=0,002)$, mas não do $\mathrm{G} 3(7,5 / 7,0)(p=0,1875)$. Constatou-se ainda que houve melhora clínica do G1 e do G2, especialmente do desconforto respiratório observado pelas retrações e tiragens.

\section{Considerações finais}

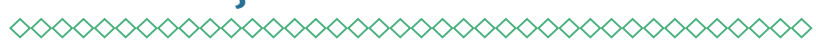

0 presente estudo vem de encontro com todos os outros que foram citados, concordando com os autores de que as técnicas de fisioterapia respiratória tapotagem, vibrocompressão, AFE, hiperinsuflação manual e aspiração beneficiam pacientes com Síndrome de Stickler com pneumonia e que se apresentam hipersecretivos proporcionando melhora nos sinais vitais e ausculta pulmonar. A fisioterapia respiratória pode contribuir para prevenção e tratamento de complicações respiratórias nesses pacientes sendo as técnicas seguras e eficazes.

Devido à escassez de literatura relacionada ao assunto, conclui-se que há necessidade de novos estudos visando uma abordagem fisioterapêutica direcionada a esse público. 


\section{Referências}

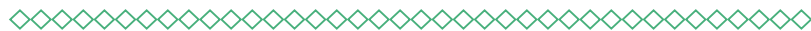

1. Chen, J. Anomalias oculares em pacientes portadores de deficiência auditiva genética. Arq. bras. Oftalmol. 2000;63(6):463.

2. Palheta-Neto $F X$, Silva DL, Almeida HG, Oliveira MS, Neiva MM, Pezzin-Palheta AC. Aspectos gerais. Pediatria Moderna. 2008;44(6).

3. Pinheiro, DC, et al. Síndromes genéticas associadas a hipocausia. Relato de três casos e revisão de literal. Revista Brasileira de Otorrinolaringologia. 2001:67(1).

4. Marques, IL, et al. Seqüência de Robin protocolo único de tratamento. Jornal de Pediatria. 2005:81(1).

5. Bethlem, N. Pneumologia. 4a ed. São Paulo: Atheneu; 2000

6. Galvão, MGA, SANTOS, MAR. Pneumonia na Infância. Pulmão. 2009:Supl. 1.
7. Santos, AG, Cerqueira Neto, ML, Costa, ACSM. Análise do Impacto da Fisioterapia Respiratória em Pacientes Pediátricos com os Sinais Clínicos apresentados na pneumonia. Revista Inspirar. 2009:1(1).

8. Tarantino, AB. Doenças pulmonares. 5a ed. Rio de Janeiro: Guanabara Koogan; 2002.

9. Tartari, JLL. Eficácia da Fisioterapia Respiratória em Lactentes Pediátricos Hospitalizados Com Pneumonia Adquirida na Comunidade: Um Ensaio Clínico Randomizado [dissertação]. Porto Alegre: Universidade Federal do Rio Grande do Sul, Faculdade de Medicina; 2003.

10. Gomes, ELFD, Costa, D. Efetividade da fisioterapia respiratória imediata em Lactentes com bronquiolite viral aguda (BVA). Técnicas atuais; técnicas convencionais e aspiração. Revista Brasileira de Fisioterapia. 2010:14(Supl. 1).

\section{Anexos}

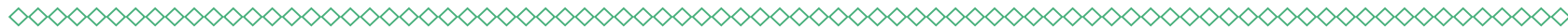

Tabela 1 - Valores de frequência cardíaca, frequência respiratória e saturação periférica de oxigênio pré e pós-técnicas de fisioterapia respiratória.

\begin{tabular}{ccc} 
Variável & Pré* & Pós* $^{*}$ \\
FC (bpm) & $121,64 \pm 19,47$ & $117,36 \pm 13,25$ \\
FR (irpm) & $55,18 \pm 16,97$ & $52,09 \pm 15,09$ \\
$\mathrm{SpO}_{2}(\%)$ & $87,91 \pm 7,78$ & $91,91 \pm 4,91$ \\
\hline
\end{tabular}

* Valores descritos em média \pm desvio padrão. FC = frequência cardíaca, FR = frequência respiratória, $\mathrm{SpO}_{2}=$ saturação periférica de oxigênio, bpm = batimentos por minuto, irpm = incursões respiratória por minuto.

Fonte: elaboração dos autores.

(clique para voltar ao texto) 